\title{
Changes in aroma and sensory profile of food ingredients smoked in the presence of a zeolite filter
}

Book or Report Section

Accepted Version

Chua, X., Uwiduhaye, E., Petroula, T., Lignou, S., Griffiths, H. D., Baines, D. A. and Parker, J. K. (2019) Changes in aroma and sensory profile of food ingredients smoked in the presence of a zeolite filter. In: Guthrie, B., Beauchamp, J. and Buettner, A. (eds.) Sex, Smoke and Spirits: The Role of Chemistry. ACS Symposium Series, pp. 67-79. doi: https://doi.org/10.1021/bk-2019-1321.ch006 Available at http://centaur.reading.ac.uk/83429/

It is advisable to refer to the publisher's version if you intend to cite from the work. See Guidance on citing.

To link to this article DOI: http://dx.doi.org/10.1021/bk-2019-1321.ch006

Publisher: ACS Symposium Series 
including copyright law. Copyright and IPR is retained by the creators or other copyright holders. Terms and conditions for use of this material are defined in the End User Agreement.

\section{www.reading.ac.uk/centaur}

\section{CentAUR}

Central Archive at the University of Reading

Reading's research outputs online 
This document is confidential and is proprietary to the American Chemical Society and its authors. Do not copy or disclose without written permission. If you have received this item in error, notify the sender and delete all copies.

\section{Changes in aroma and sensory profile of food ingredients smoked in the presence of a zeolite filter}

\begin{tabular}{|c|c|}
\hline Journal: & ACS Books \\
\hline Manuscript ID & bk-2018-007633.R1 \\
\hline Manuscript Type: & Symposium Series Chapter \\
\hline $\begin{array}{r}\text { Date Submitted by the } \\
\text { Author: }\end{array}$ & 01-Apr-2019 \\
\hline Complete List of Authors: & $\begin{array}{l}\text { Chua, XinLing; University of Reading, Food and Nutritional Sciences } \\
\text { Uwiduhaye, Elizabeth; University of Reading, Food and Nutritional } \\
\text { Sciences } \\
\text { Tsitlakidou, Petroula; University of Reading, Food and Nutritional } \\
\text { Sciences; Besmoke Ltd } \\
\text { Lignou, Stella; University of Reading, Food and Nutritional Sciences } \\
\text { Griffiths, Huw; Besmoke Ltd } \\
\text { Baines, David; Baines Food Consultancy Ltd } \\
\text { Parker, J.K.; University of Reading, Food and Nutritional Sciences }\end{array}$ \\
\hline
\end{tabular}

\section{SCHOLARONE Manuscripts}


During smoking, formation of desirable smoky compounds and carcinogenic polycyclic aromatic hydrocarbons (PAH) are inextricably linked. We have previously developed a zeolite filter technology (PureSmoke Technology or PST) that reduces the PAH content of a smoke stream, particularly reducing the concentration of benzo[a]pyrene, a known carcinogen, by up to $93 \%$. The aim of this work was to determine whether there were changes in the volatile and sensory profiles of ingredients smoked using PST compared to the traditional smoking process (Trad). Smoked tomato flakes (either PST or Trad) were added to either low-fat or full-fat cream cheese for sensory profiling and consumer preference tests, and volatile analysis was carried out using solid phase microextraction (SPME) followed by gas chromatography-mass spectrometry (GC-MS). The sensory analysis showed a significant decrease $(p<0.01)$ in bitterness

\section{RESERVE THIS SPACE}


when the PST was employed and a significant decrease in overall smoky aroma and flavor $(p<0.001)$, which resulted in an increase in the perception of cheesy aroma and flavor. This was consistent with a decrease in many of the smoky aroma compounds, particularly the guaiacols. However, consumer preference tests showed that there was no adverse effect on the flavor of the products, and there was even a tendency for the PST product to be preferred to the Trad product $(p=0.096)$. The smoke compounds were quantitated and compared in smoked tomato paste. Odor activity values (OAVs) calculated from the literature thresholds suggested that guaiacol and 4alk(en)yl-substituted guaiacols are likely to be among the most highly odor-active compounds in these smoked ingredients.

\section{Introduction}

The use of smoke for preservation has become secondary to its use in creating unique smoky aromas and flavors in foods. Smoked ingredients are used widely by the food industry to impart a characteristic smoky flavor to rubs, dips, marinades, soups, and snacks. The volatile components of aqueous smokes have been studied extensively ${ }^{1}$ as have the smoky aroma compounds in various fish ${ }^{2,3}$ and cheeses. ${ }^{4-6}$ The highly desirable smoky flavor is generated by the burning of wood chips, of varying origin, at high temperatures $\left(400-1000{ }^{\circ} \mathrm{C}\right)$. Phenolic compounds such as syringol and guaiacol are essential for the sensory characteristics of smoke, and the gas chromotography-olfactometry (GC-O) of smoked fish has shown many more important compounds that contribute to the smoky aroma. ${ }^{7,8}$

However, the smoking process also results in the formation of polycyclic aromatic hydrocarbons (PAHs). These PAHs are a series of fused benzene ring structures, and many of these are classified as Class 2 carcinogens. One of these PAHs, benzo[a]pyrene, is a known carcinogen, and epidemiological evidence has implicated smoked foods in an increased risk of cancer in humans. ${ }^{9}{ }^{10}$ In 2015, Griffiths, Baines, and Parker-Gray ${ }^{11}$ developed a filtration technology based on zeolites (PureSmoke Technology or PST) whereby up to 93\% of the PAHs could be removed from a smoke stream. ${ }^{12}$ Comparison of the headspace of oils smoked either traditionally (Trad) or through the filter (PST) showed that generally, the low molecular weight aroma compounds were not removed by the filter. However, many of the components of smoke most likely to contribute to the smoky flavor were partially removed by the filter, particularly the guaiacols and 
the eugenols. Preliminary sensory testing of smoked tomato ketchup suggested that the PST product had a sweeter aroma than the Trad product. Differences in the smoky, rubbery, and tar aroma and flavor were not observed, despite a decrease in smoky aroma compounds; these differences were possibly masked by the intensity of the neat ketchup. The changes in flavor warrant further investigation since it is important to establish that PST does not adversely affect the flavor of the product. In this study, we used tomato flakes that were Trad or PST smoked. The flakes were finely ground and added to cream cheese for sensory, consumer, and instrumental analysis.

\section{Materials and Methods}

\section{Materials}

Tomato flakes were purchased from Camstar Ingredients (Eye, U.K.), and tomato paste was purchased from Silbury Marketing (Banbury, U.K.). They were smoked with oak chips obtained from Ashwood Smoking Chips (Kettering, U.K.) using either PST or Trad smoking. Portions of the smoked tomato flakes were ground with a pestle and mortar and sieved. The fraction collected from sieve size $3(355 \mu \mathrm{m}-1 \mathrm{~mm})$ was added to either low-fat or full-fat cream cheese for volatile analysis, sensory profiling, and consumer testing. The tomato paste was used to quantitatively compare the aroma compounds derived from either PST or Trad smoking.

Two types of cream cheese were used in order to provide four samples for sensory profiling, rather than just two. Tubs ( $180 \mathrm{~g})$ of Philadelphia Original $(21 \%$ fat) and Philadelphia Light (11\% fat) (Mondelez, Uxbridge, UK) were purchased from one local supermarket, ensuring that the tubs for each product were from one batch. Ground smoked tomato flakes were added to the cheese $(2.5 \% \mathrm{w} / \mathrm{w})$, mixed thoroughly, and returned to the container to equilibrate overnight before tasting or analysis. Thus, four samples of cream cheese with smoked tomato flakes were prepared: low-fat Trad, low-fat PST, full-fat Trad, and full-fat PST. All sensory references were purchased from a local supermarket.

2-Octanol, 2,3-butanedione (diacetyl), 3-hydroxybutanone (acetoin), acetic acid, benzeneacetaldehyde, 6-methyl-5-hepten-2-one, 2-acetylpyrrole, phenol, 5butyl-4-methyloxolan-2-one (whiskey lactone, mix of two isomers), 4-methyl-2methoxyphenol (4-methylguaiacol), 4-ethyl-2-methoxyphenol (4-ethylguaiacol), 2-methoxy-4-propylphenol (4-propylguaiacol), 4-ethenyl-2-methoxyphenol (4vinylguaiacol), 2,6-dimethoxyphenol (syringol), 2-hydroxy-3-methyl-2cyclopenten-1-one (cyclotene), and 2,6-dimethylphenol were purchased from Sigma-Aldrich (Poole, U.K.). 2-Furaldehyde (furfural), 1-(2-furyl)ethanone (2- 
acetylfuran), 5-methyl-2-furaldehyde (5-methylfurfural), 4-methylphenol ( $p$ cresol), 2-methylphenol (o-cresol), and 2-methoxyphenol (guaiacol) were obtained from Fisher Scientific (Loughborough, U.K.). 2-Methoxy-4-[(1E)-1propen-1-yl]phenol ([E]-isoeugenol) containing $1 \%$ of the $Z$-isomer and 4-allyl2-methoxyphenol (eugenol) were purchased from Givaudan (Milton Keynes, U.K.). 2-Isopropyl-5-methylphenol (thymol) was purchased from Mane (London, U.K.).

\section{Volatile Analysis of Cream Cheese with Added Smoked Tomato Flakes}

Samples of cream cheese $(20 \mathrm{~g})$ were incubated in a Duran bottle at $40{ }^{\circ} \mathrm{C}$ for $30 \mathrm{~min}$. A triple-phase Stabilflex fiber (PDMS/Carboxen/DVB, $11 \mathrm{~mm}$, from Supelco, Poole, U.K.) was exposed to the headspace for a further $30 \mathrm{~min}$ to extract the volatile compounds. Gas chromatography-mass spectrometry (GC-MS) analysis was conducted using a $5972 \mathrm{MS}$ coupled to an Agilent Technologies 5890 GC (Agilent, Santa Clara, CA, U.S.A.). Each extraction was injected in splitless mode onto a J\&W DB-WAX column $(30 \mathrm{~m} \times 250 \mu \mathrm{m} \times 1 \mu \mathrm{m}$ film thickness) (Agilent, Santa Clara, CA), and the following temperature program was employed: $2 \mathrm{~min}$ at $40{ }^{\circ} \mathrm{C}$, then raised to $250{ }^{\circ} \mathrm{C}$ at a rate of $5{ }^{\circ} \mathrm{C} / \mathrm{min}$. The flow rate of the helium carrier gas was $0.9 \mathrm{~mL} / \mathrm{min}$. Mass spectra were measured in electron ionization mode at $70 \mathrm{eV}$. The scan range was from $m / z$ 29-300. Samples $(20 \mathrm{~g})$ of unsmoked tomato flakes, unsmoked tomato paste, and unflavored fullfat and low-fat cheese were also analyzed for comparison purposes. Volatiles were identified by comparing each mass spectrum with the spectrum of the authentic compounds analyzed in our laboratory. To confirm the identification, the linear retention index (LRI) was calculated for each volatile compound using the retention times of a homologous series of $\mathrm{C}_{6}-\mathrm{C}_{25} n$-alkanes and by comparing the LRI with those of authentic compounds analyzed under similar conditions. Samples were also analyzed on a non-polar DB5 column $(30 \mathrm{~m} \times 250 \mu \mathrm{m} \times 1 \mu \mathrm{m}$ film thickness) (Agilent, Santa Clara, CA) using the same temperature program to further confirm their identity. Rather than adding an internal standard into a semi-solid cheese, an external standard of 2-octanol was injected every six samples. The deviation in the peak areas was no greater than $10 \%$ and there was no observed trend.

\section{Sensory Profiling of Cream Cheese with Added Smoked Tomato Flakes}

A panel of nine trained assessors (90\% women aged 35-60), each with a minimum of six months' experience, was used to develop a quantitative sensory profile for describing the sensory characteristics of the four different samples of cream cheese. Following an initial collection of terms, reference materials were 
provided to help assessors standardize the terms and reach a consensus vocabulary. The references included a range of smoked foods (smoked haddock, smoked mackerel, kippers, and smoked cheese) as well as smoky bacon snacks, burnt wood, burnt paper, and burnt matches. The final vocabulary consisted of 5 aroma terms, 18 taste/flavor terms, 2 mouthfeel terms, and 1 after-effect term. The quantitative sensory assessment took place in individual sensory booths (under red light) at $22 \pm 0.5^{\circ} \mathrm{C}$. Assessors were provided with a glass of warm water and unsalted crackers (Carr's of Carlisle, Carlisle, U.K.) for palate cleansing between samples. Samples $(\sim 2-3 \mathrm{~g})$ were presented to the assessors on a plastic teaspoon in a balanced order and randomly allocated. The assessors were asked to smell, taste, and swallow the samples and score them on appearance, odor, taste, flavor, and mouthfeel attributes. After a 45 -s pause, they scored the samples for after-effects. The intensity of each attribute was recorded on a $150 \mathrm{~mm}$ unstructured line scale (scaled 0-100) and all data were collected using Compusense @ Hand (Compusense Inc., Guelph, Ontario, Canada). A duplicate assessment was carried out in a separate session.

\section{Consumer Preference of Cream Cheese with Added Smoked Tomato Flakes}

Consumer testing was carried out as described by IFT-SED ${ }^{13}$ in individual sensory booths. A total of 115 naïve consumers (70\% women aged 19-63; mean age of 32) carried out a paired preference test. They were served two samples of full-fat cream cheese; approximately $2-3 \mathrm{~g}$ of cheese was placed on the tip of a plastic teaspoon. One cheese sample contained $2.5 \%$ Trad smoked tomato flakes and the other contained $2.5 \%$ PST smoked tomato flakes as described for sensory profiling purposes. The consumers tasted the two samples in a balanced and randomly allocated order and were asked to select their preferred sample.

\section{Quantitation of Volatiles in Smoked Tomato Paste}

The aroma compounds generated during the smoking process were quantified in tomato paste using solid phase microextraction (SPME) followed by GC-MS analysis. External calibration curves were prepared with unsmoked tomato paste containing a cocktail of standards at appropriate concentrations. Single standards were prepared in methanol (or acetone for compounds in cocktail C) to form stock solutions $(200 \mathrm{mg} / \mathrm{L})$, from which four standard cocktails were prepared in highperformance liquid chromatography (HPLC) water containing analytes at 10 $\mathrm{mg} / \mathrm{L}$ unless otherwise indicated. Cocktail A contained a mixture of guaiacol, 4methylguaiacol, 4-ethylguaiacol, syringol $(30 \mathrm{mg} / \mathrm{L})$, and cyclotene $(30 \mathrm{mg} / \mathrm{L})$. Cocktail B contained a mixture of phenol, 2-methylphenol, 4-methylphenol, 2,6dimethylphenol, eugenol, and $(E)$-isoeugenol. Cocktail $\mathrm{C}$ contained a mixture of 
furfural, 5-methylfurfural, and 2-acetylfuran. Cocktail D contained a mixture of 4-vinylguaiacol (5 mg/L) and whiskey lactone ( $5 \mathrm{mg} / \mathrm{L})$. Five serial dilutions $(1: 1)$ of these cocktails were prepared with HPLC grade water. Samples for calibration were made up of $1.00 \pm 0.01 \mathrm{~g}$ of tomato paste, $1.0 \mathrm{~mL}$ of cocktail, and $1 \mathrm{uL}$ of thymol (internal standard of $5 \mathrm{~g} / \mathrm{L}$ ). All vials were mixed using a Velp F202A0175 Wizard Vortex Mixer at $3000 \mathrm{rpm}$ for $30 \mathrm{~s}$ and analyzed in triplicate by SPME at each dilution. For the smoked tomato paste samples (Trad and PST), $1.00 \pm 0.01$ $\mathrm{g}$ was diluted with $1 \mathrm{~mL}$ of water; $1 \mathrm{uL}$ of internal standard was added and the samples were analyzed in triplicate under the same conditions as the standards.

SPME GC-MS was carried out using a DVB/Carboxen/PDMS Stableflex fiber (11mm, SupelCo, Poole, U.K.) and GC-MS was performed on an Agilent 7890-5975C GC-MS equipped with a Zebron ZB-5MSi column $(30 \mathrm{~m} \times 0.25 \mathrm{~mm}$ i.d. $\times 1 \mu \mathrm{m}$ film thickness). Samples were equilibrated at $40{ }^{\circ} \mathrm{C}$ for $10 \mathrm{~min}$ with intermittent stirring prior to exposing the fiber for $10 \mathrm{~min}$ at $40^{\circ} \mathrm{C}$. The fiber was desorbed in the injection port for $20 \mathrm{~min}$ and the volatile compounds were analyzed. Helium was the carrier gas at $1.2 \mathrm{~mL} / \mathrm{min}$. After desorption, the oven was maintained at $40{ }^{\circ} \mathrm{C}$ for $5 \mathrm{~min}$, then raised to $250{ }^{\circ} \mathrm{C}$ at $4{ }^{\circ} \mathrm{C} / \mathrm{min}$. Mass spectra were recorded in electron ionization mode at $70 \mathrm{eV}$ and at a source temperature of $230{ }^{\circ} \mathrm{C}$. A scan range of $\mathrm{m} / \mathrm{z} 29-400$ with a scan time of $0.69 \mathrm{~s}$ was used and the data were controlled and stored by the ChemStation system.

Good linearity was observed for all compounds except 4-vinylguaiacol and whisky lactone which were close to the limit of detection for the method, and their calibrations were based on fewer points $\left(R^{2}\right.$ for these were 0.61 and 0.84 , respectively). Otherwise, $\mathrm{R}^{2}$ was always greater than 0.9 and generally greater than 0.95 . For $(Z)$-isoeugenol, the calibration curve for $(E)$-isoeugenol was used. For the unresolved 3- and 4-methylphenols, the calibration curve for 4methylphenol was used.

\section{Statistical Analysis}

The data for the volatile analyses were analyzed with XLStat (AddinSoft, Paris, France, 2015.6.01) using one-way analysis of variance (ANOVA), and post-hoc multiple pairwise comparisons were carried out using the Fisher's least significant difference (LSD) test with the significance level set at $p=0.05$. Twoway ANOVA was used to determine the significance of fat type and smoke technology. For the sensory data, SENPAQ version 3.2 (Qi Statistics, Reading, U.K.) was used to carry out the two-way ANOVA where main effects were tested against the sample by using assessor interaction. Multiple pairwise comparisons were done using the Fisher's LSD at $p=0.05$. Principal component analysis (PCA) was carried out on the sensory data in XLStat with the volatile data used 
as supplementary data. Results from the paired preference test were evaluated using the binomial model in V-Power (Jesionka; macro for Microsoft Excel).

\section{Results}

\section{Flavor Changes in Smoked Tomato Flakes Added to Cream Cheese}

Volatile Analysis

Twenty compounds were selected for comparison between samples based on published GC-O data, ${ }^{8}$ their abundance, and their relevance to cheese and smoke flavor (Table 1). Comparing just the peak areas of the Trad and the PST in fullfat cheese, all the smoke-derived compounds had smaller peak areas in PST compared to those in the Trad, 11 of these being significant at $p<0.05$ and the remainder at $p<0.1$. These were all compounds that were observed in smoked oil ${ }^{12}$ including furfurals (2), guaiacols (5), eugenols (3), 4-methylphenol, 2acetylpyrrole, syringol, and cyclotene. In the low-fat cheese, the same trends were observed, except for 2-acetylpyrrole and $(Z)$-isoeugenol where the differences were either not significant or not consistent between the two cheeses. This decrease in smoke-derived compounds is similar to the decrease observed by Parker et al. ${ }^{12}$ where sunflower oil was either Trad smoked or filtered through zeolite. However, in the smoked oils, furfural and 5-methylfurfural did not decrease when the filter was employed. 
Table 1. Relative Peak Areas of Selected Volatile Compounds Detected in the Headspace of Low-Fat or Full-Fat Cream Cheese Containing $2.5 \%$ w/w Trad or PST Ground Tomato Flakes.

\begin{tabular}{|c|c|c|c|c|c|c|c|c|}
\hline Compound & $\begin{array}{l}L R I \\
D B 5\end{array}$ & $\begin{array}{l}\text { LRI } \\
\text { Wax }\end{array}$ & $\begin{array}{r}\text { Full } \\
\text { Che }\end{array}$ & & $\begin{array}{l}\text { Low } \\
\text { Ch }\end{array}$ & & $S^{a}$ & $S^{b}$ \\
\hline & & & Trad & $P S T$ & Trad & $P S T$ & & \\
\hline 3-Butanedione & 586 & 961 & $26^{c}$ & 29 & 29 & 33 & & \\
\hline 2-Heptanone & 892 & 1167 & $3.3 \mathrm{a}$ & $3.4 \mathrm{a}$ & $2.5 \mathrm{~b}$ & $3.0 \mathrm{a}$ & $\mathrm{ns}$ & ** \\
\hline Hydroxybutanone & 708 & 1283 & $75 b$ & $75 b$ & $80 \mathrm{~b}$ & $112 \mathrm{a}$ & & ** \\
\hline $\begin{array}{l}\text { 6-Methyl-5-hepten-2- } \\
\text { one }\end{array}$ & 986 & 1330 & $9.6 \mathrm{~b}$ & $12 \mathrm{~b}$ & $12 \mathrm{~b}$ & $22 \mathrm{a}$ & *** & *** \\
\hline cetic acid & 602 & 1458 & $25 \mathrm{c}$ & $26 \mathrm{c}$ & $35 \mathrm{~b}$ & $46 \mathrm{a}$ & * & *** \\
\hline Furfural & 833 & 1462 & $5.0 \mathrm{~b}$ & $2.9 \mathrm{c}$ & $6.2 \mathrm{a}$ & $3.5 \mathrm{c}$ & *** & * \\
\hline 5-Methylfurfural & 965 & 1571 & $2.3 \mathrm{a}$ & $0.9 \mathrm{c}$ & $2.5 \mathrm{a}$ & $1.3 \mathrm{~b}$ & *** & \\
\hline Benzenacetaldehyde & 1048 & 1640 & $2.1 \mathrm{a}$ & $2.5 \mathrm{~b}$ & $3.4 \mathrm{a}$ & $3.9 \mathrm{a}$ & ns & **** \\
\hline Cyclotene & 1030 & 1830 & $2.2 \mathrm{a}$ & $0.3 \mathrm{c}$ & $1.7 \mathrm{~b}$ & $0.3 \mathrm{c}$ & **** & *** \\
\hline Guaiacol & 1094 & 1859 & $18 \mathrm{a}$ & $4.7 \mathrm{c}$ & $19 \mathrm{a}$ & $7.1 \mathrm{~b}$ & *** & * \\
\hline -Methylguaiacol & 1198 & 1956 & $14 \mathrm{a}$ & $3.2 \mathrm{~b}$ & $16 \mathrm{a}$ & $6.1 \mathrm{~b}$ & **** & * \\
\hline 2-Acetylpyrrole & 1061 & 1970 & $4.4 \mathrm{a}$ & $3.0 \mathrm{~b}$ & $3.9 \mathrm{a}$ & $4.3 \mathrm{a}$ & * & ns \\
\hline 4-Ethylguaiacol & 1286 & 2029 & $9.4 \mathrm{a}$ & $1.9 \mathrm{~b}$ & $11 \mathrm{a}$ & $3.9 \mathrm{~b}$ & **** & \\
\hline Methylphenol & 1072 & 2090 & $2.2 \mathrm{a}$ & $0.6 \mathrm{c}$ & $2.3 \mathrm{a}$ & $0.9 \mathrm{~b}$ & *** & * \\
\hline 4-Propylguaiacol & 1375 & 2108 & $1.9 \mathrm{a}$ & $0.3 \mathrm{~b}$ & $1.9 \mathrm{a}$ & $0.7 \mathrm{~b}$ & *** & ns \\
\hline Eugenol & 1365 & 2166 & 0.9 & 0.3 & 0.7 & 0.5 & & ns \\
\hline Vinylguaiacol & 1322 & 2195 & $0.3 b$ & $0.1 \mathrm{~b}$ & $1.5 \mathrm{a}$ & $0.3 \mathrm{~b}$ & ** & \\
\hline -Isoeugenol & 1417 & 2254 & 0.5 & 0.1 & 0.3 & 0.3 & * & ns \\
\hline ringol & 1357 & 2263 & $4.6 \mathrm{a}$ & $1.1 \mathrm{~b}$ & $4.7 \mathrm{a}$ & $2.3 \mathrm{~b}$ & *** & ns \\
\hline (E)-Isoeugenol & 1460 & 2348 & $1.2 \mathrm{a}$ & $0.2 \mathrm{~b}$ & $1.3 \mathrm{a}$ & $0.6 \mathrm{~b}$ & $* * *$ & ns \\
\hline
\end{tabular}

${ }^{a}$ Significance, obtained from ANOVA, that there is a difference between the Trad and PST samples where $\mathrm{ns}=$ no significant difference $(\mathrm{p}>0.05)$; *sig is $0.01<p \leq 0.05 ; * *$ sig is $0.001<p \leq 0.01$; and $* * *$ sig is $p \leq 0.001$.

${ }^{b}$ Significance, obtained from ANOVA, that there is a difference between the full-fat and the low-fat cheese samples.

${ }^{c}$ Mean peak areas $\times 10^{4} \mathrm{AU}(\mathrm{n}=3)$; means in the same row that are not labelled with the same letters are significantly different $(p=0.05)$.

In the full-fat cheese, the smoking technology had no impact on the compounds that were already present in the unflavored cream cheese $(2,3-$ butanedione, 2-heptanone, 3-hydroxybutanone, and acetic acid); however, in the low-fat cheese, there was a tendency for these compounds to be higher in the PST sample than the Trad sample. This was also the case for 6-methyl-5-heptene-2one which is a carotenoid-derived compound found in the unsmoked tomato flakes. 
Although the primary aim of the experiment was not to compare flavor release in full-fat and low-fat cream cheese, the data for the PST cheese showed a significant increase in flavor release for nine compounds in the low-fat cheese compared to the full-fat cheese, with a similar trend for another nine. This is consistent with current understanding of the role of fat content with regard to flavor release. This has mainly been demonstrated in dairy yogurts ${ }^{14}$ or ice cream, ${ }^{15}$ but for hydrophobic aroma compounds with relatively high $\log p$ values, it is well established that a decrease in fat content will promote partitioning into the headspace and increase flavor release. However, with the Trad cheese, this effect was greatly diminished, and only three compounds (acetic acid, furfural, and 4-vinylguaiacol) showed a significant increase in the low-fat cheese.

\section{Sensory Analysis}

The sensory data showed that there were significant differences between the cheese samples for 12 of the 25 attributes (Table 2). One key difference was the significant reduction in the bitter taste when the PST was applied, which is perhaps a result of the filter holding back non-volatile bitter compounds in the tar fraction that does not pass through the filter. The compounds associated with smoke were consistently higher in Trad compared to PST, particularly the overall smoky aroma, flavor and aftertaste, the bonfire aroma and flavor, and the diesel flavor. This is consistent with the instrumental volatile data that showed a higher concentration of typical smoky aroma compounds in the Trad samples. On the other hand, the cheesy aroma was significantly higher in the PST samples. In fullfat cheese, the change in smoke technology did not significantly alter the concentration of the compounds associated with the cheese suggesting that these compounds were masked by the high levels of smoke compounds in the full-fat Trad product, which makes them more prominent in the full-fat PST sample. In low-fat cheese, the compounds associated with cheese did increase in the PST product, which is consistent with an increase in aroma in this product. Either or both of these mechanisms could explain the increase in cheesy aroma in the PST products.

When these data are viewed on a PC plot, the correlations are clear (Figure 1). All the smoky aroma compounds are positioned to the far right of PC1: an area associated with the low-fat Trad product which a) contains more smoky compounds than PST, and b) is based on the low-fat cheese which promotes the release of more smoky compounds. PC1 separates the Trad from the PST (with more cheesy and dairy notes associated with PST), which is consistent with less masking from the smoke volatiles. Interestingly, 2,3-butanedione and 3hydroxybutanone which have buttery creamy and dairy notes were highly correlated with the sour yogurt note as was acetic acid, which contributes the 
"sour" to this attribute. The sun-dried tomato flavor attribute is associated with 6-methyl-5-hepten-2-one, a carotenoid-derived compound found in the tomato flake.

Table 2. Mean Panel Scores for Sensory Attributes Found in Low-Fat or Full-Fat Cream Cheese Containing $2.5 \%$ w/w Trad or PST Ground Tomato Flakes.

\begin{tabular}{|c|c|c|c|c|c|}
\hline Sensory Attribute & Full-F & heese & Low-I & heese & $\operatorname{Sig}^{a}$ \\
\hline Aroma & Trad & $P S T$ & Trad & $P S T$ & \\
\hline Overall smokiness & $33 \mathrm{a}^{b}$ & $16 b$ & $41 \mathrm{a}$ & $23 b$ & *** \\
\hline Bonfire & $25 \mathrm{~b}$ & $12 \mathrm{c}$ & $33 a$ & $15 \mathrm{c}$ & *** \\
\hline Ash & $4.4 \mathrm{ab}$ & $1.3 \mathrm{~b}$ & $6.9 \mathrm{a}$ & $2.0 \mathrm{~b}$ & $*$ \\
\hline $\begin{array}{l}\text { Cheesy } \\
\text { Taste }\end{array}$ & $19 \mathrm{bc}$ & $33 \mathrm{a}$ & $17 \mathrm{c}$ & $26 a b$ & $* *$ \\
\hline Sweet & 18 & 19 & 16 & 18 & ns \\
\hline Salty & 19 & 18 & 21 & 20 & ns \\
\hline Umami & 30 & 27 & 30 & 32 & ns \\
\hline Bitter & $7.6 \mathrm{ab}$ & $5.3 b$ & $9.7 \mathrm{a}$ & $7.7 b$ & $*$ \\
\hline Sour & 13 & 15 & 13 & 15 & ns \\
\hline Flavor & & & & & \\
\hline Overall smokiness & $40 \mathrm{a}$ & $20 c$ & $46 a$ & $30 \mathrm{~b}$ & $* * *$ \\
\hline Bonfire & $28 \mathrm{a}$ & $13 b$ & $36 \mathrm{a}$ & $20 \mathrm{~b}$ & *** \\
\hline Paprika & 14 & 12.8 & 15 & 12.3 & ns \\
\hline Ash & $3.7 b$ & $1.7 \mathrm{~b}$ & $8.1 \mathrm{a}$ & $2.2 b$ & $* *$ \\
\hline Smoked fish & $19 \mathrm{a}$ & $8.5 b$ & $20 \mathrm{a}$ & $15 \mathrm{a}$ & $* *$ \\
\hline Diesel & $4.2 \mathrm{a}$ & $0.6 \mathrm{~b}$ & $4.1 \mathrm{a}$ & $0.8 \mathrm{~b}$ & ${ }^{*}$ \\
\hline Sundried tomato & 16 & 17 & 15 & 20 & ns \\
\hline Dairy & 24 & 29 & 23 & 26 & ns \\
\hline Sour yogurt & 13 & 13 & 13 & 16 & ns \\
\hline Spicy & 13 & 10 & 16 & 13 & ns \\
\hline Smoked bacon & 17 & 11 & 20 & 15 & ns \\
\hline Cheesy & $27 \mathrm{ab}$ & $32 \mathrm{a}$ & $20 \mathrm{~b}$ & $28 \mathrm{ab}$ & $*$ \\
\hline $\begin{array}{l}\text { Balanced } \\
\text { After-effects }\end{array}$ & 44 & 46 & 44 & 46 & ns \\
\hline Mouthcoating & 34 & 30 & 31 & 31 & ns \\
\hline Warming & 9.4 & 6.6 & 10 & 7.8 & ns \\
\hline Smoked food & $26 \mathrm{a}$ & $14 b$ & $30 \mathrm{a}$ & $15 b$ & $* * *$ \\
\hline
\end{tabular}

${ }^{a}$ Significance, obtained from ANOVA, that there is a difference between the mean scores where $\mathrm{ns}=$ no significant difference $(p>0.05) ;{ }^{*} \operatorname{sig}$ is $0.01<p \leq 0.05 ; * *$ sig is $0.001<p$ $\leq 0.01$; and $* * * \operatorname{sig}$ is $p \leq 0.001$.

${ }^{b}$ Mean panel scores ( $\mathrm{n}=9$ in duplicate); means in the same row not labelled with the same letters are significantly different $(p=0.05)$. 
Overall the sensory profiling showed a decrease in smoky notes and a decrease in bitterness when the PST was applied. As a result, more notes from the cheese and the tomato flakes were perceived by the panelists.

Figure 1. PC1 vs. PC2 of sensory attributes (italics) for cream cheese with added smoked tomato flakes ( $F=$ full-fat, $L=$ low-fat, $T=$ traditional process, $P=$ PST) with volatile data overlaid.

\section{Consumer Analysis}

Sensory profiling, however, is not hedonic, so we recruited a panel of 115 naïve volunteers to indicate which product they preferred when given a choice of full-fat Trad or full-fat PST. Of these volunteers, 65 preferred the PST product 
and 50 preferred the Trad (ratio of 57:43). This indicates that there is no adverse effect on flavor when the PST is applied and that there is tendency for the PST to be preferred to Trad at $p=0.096$. Thus, the removal of PAHs from smoke using PST does not adversely affect the flavor and may also improve it. Other food ingredients are under test.

\section{Quantitative Comparison in Tomato Paste of Aroma Compounds Generated during either Trad or PST}

However, questions remain as to why the reduction in some of the aroma compounds may improve the flavor and which of these compounds are the key contributors to the less desirable aroma attributes such as ash and diesel. With this in mind, we quantitated the aroma compounds in tomato paste that had been smoked using either Trad or PST. Seventeen compounds were selected based on the literature where $\mathrm{GC}-\mathrm{O}$ was used to determine odor-active compounds in smoked foods. ${ }^{8}$ Table 3 shows the concentration of each compound found in the smoked tomato paste. Furfural and 5-methylfurfural were by far the most abundant compounds in the smoked tomato paste, but not necessarily the most odor-active. In order to estimate the odor activity of these compounds, literature thresholds in water were employed, where possible, to calculate odor activity values $(\mathrm{OAV}$, the concentrations in $\mathrm{ug} / \mathrm{kg}$ divided by the odor thresholds in $\mathrm{ug} / \mathrm{kg}$ ). Of those compounds where thresholds were available, guaiacol had the highest odor activity, which is consistent with data taken from Varlet et al. ${ }^{8}$ showing that guaiacol had the highest average intensity by GC-O in smoked salmon, despite very different matrices. According to Table 3, the next most odoractive compounds are likely to be eugenol and 4-methyl-, 4-ethyl-, and 4vinylguaiacols; in the smoked salmon, ${ }^{8} 4$-methylphenol, 2 -acetylfuran, and (E)isoeugenol were the next most intense. No odor thresholds in water were available for $(E)$-isoeugenol, but 4-methylphenol and 2-acetylfuran were much less odoractive if water thresholds are used. The odor threshold for whiskey lactone was determined in a water-ethanol mix and is therefore likely to be overestimated since the ethanol is likely to reduce the partitioning into the headspace. This would result in an underestimation of the OAV. Schranz et al. ${ }^{16}$ have recently reported thresholds in air for many of these compounds. Applying these thresholds to compare OAVs (with arbitrary units) for selected compounds shows that guaiacol is again the most odor-active followed by 4-ethylguaiacol, 4-methylguaiacol, and $(Z)$-isoeugenol. There are clearly major limitations associated with using literature thresholds from different matrices for calculating OAVs. What is clear though is the fact that the guaiacols, and perhaps also the eugenols, are important contributors to the aroma of the smoked tomato pastes. It is less likely that the furans, the phenols, and the whiskey lactone contribute, but this requires a full sensomics analysis to confirm the role of these compounds in smoky flavor and 
identify the key differences that make Trad and PST smoke smell slightly different.

Table 3. Concentration (ug/kg) and Approximated OAV of Aroma Compounds in Trad or PST Tomato Paste

\begin{tabular}{|c|c|c|c|c|c|c|c|}
\hline \multirow[t]{2}{*}{ Compound } & \multirow{2}{*}{$\begin{array}{l}L R I \\
D B 5\end{array}$} & \multirow{2}{*}{$\begin{array}{c}\text { Threshold } \\
\text { ug/kg }\end{array}$} & \multirow{2}{*}{\multicolumn{2}{|c|}{$\begin{array}{c}\text { Concentration }^{b} \\
u g / k g\end{array}$}} & \multicolumn{2}{|c|}{$O A V$} & $S^{c}$ \\
\hline & & & Trad & & Trad & PST & \\
\hline Guaiacol & 1095 & 3 & 750 & 400 & 250 & 133 & *** \\
\hline Eugenol & 1366 & 6 & 140 & 70 & 23 & 12 & *** \\
\hline 4-Methylguaiacol & 1200 & 90 & 670 & 360 & 7.4 & 4.0 & *** \\
\hline 4-Ethylguaiacol & 1286 & 50 & 230 & 110 & 4.6 & 2.2 & *** \\
\hline 4-Vinylguaiacol & 1323 & 18 & 3.3 & 1.7 & 3.3 & 1.7 & ns \\
\hline 2-Furfural & 836 & 3000 & 3070 & 2460 & 1.0 & 0.8 & *** \\
\hline Cyclotene & 1028 & 300 & 220 & 110 & 0.7 & 0.4 & $\mathrm{~ns}$ \\
\hline 3/4-Methylphenol & 1073 & 55 & 20 & 10 & 0.4 & 0.2 & *** \\
\hline Syringol & 1358 & 1850 & 380 & 240 & 0.2 & 0.1 & ns \\
\hline Phenol & 978 & 5900 & 650 & 400 & 0.1 & 0.1 & *** \\
\hline Whiskey lactone $^{d}$ & 1298 & 790 & 40 & 20 & 0.05 & 0.03 & *** \\
\hline 2-Methylphenol & 1053 & 650 & 30 & 10 & 0.05 & 0.02 & *** \\
\hline 2-Acetylfuran & 913 & 10000 & 110 & 70 & 0.01 & 0.01 & *** \\
\hline 5-Methylfurfural & 967 & na & 3720 & 2890 & & & ** \\
\hline 2,6-Dimethylphenol & 1025 & na & 50 & 20 & & & *** \\
\hline (E)-isoeugenol & 1461 & na & 770 & 360 & & & ** \\
\hline (Z)-isoeugenol & 1418 & na & 380 & 170 & & & *** \\
\hline
\end{tabular}

${ }^{a}$ Threshold in water $(\mathrm{ug} / \mathrm{kg})^{17}$; na = not available.

${ }^{b}$ Mean concentration ug $/ \mathrm{kg}(\mathrm{n}=3)$.

cProbability, obtained from ANOVA, that there is a difference between the Trad and PST samples where $\mathrm{ns}=$ no significant difference $(p>0.05)$; and $* * *$ significant at $p \leq 0.001$.

${ }^{d}$ Odor threshold in water-ethanol mixture (6:4 by vol). ${ }^{18}$

\section{Overall Conclusion}

A new technology (PST) has been developed to remove carcinogenic PAHs from smoke streams used for smoking food ingredients. The aim of this chapter was to determine whether the PST had a detrimental effect on flavor. Tomato flakes were smoked using either Trad or PST, and the smoked tomato flakes were presented in either full-fat or low-fat cream cheese. Using sensory profiling, we demonstrated that in both cases there was a small but significant reduction in 
bitterness when PST was used to filter the smoke prior to smoking the tomato flakes. There was also a significant reduction in the smoky aroma and flavor attributes, and this was confirmed using instrumental analysis. However, when the two full-fat products were compared in a consumer preference test $(n=115)$, there was no clear preference for either product. Thus, we conclude that when PST is employed to reduce the concentration of carcinogenic PAHs in products such as smoked tomato flakes (or other spices), it also can reduce some of the bitterness associated with the smoking process. There is a minor impact on the aroma profile, but this did not have an impact on consumer preference.

\section{References}

1. Guillen, M. D.; Manzanos, M. J. Characteristics of Smoke Flavorings Obtained from Mixtures of Oak Quercus sp. Wood and Aromatic Plants Thymus vulgaris L. and Salvia lavandulifolia Vahl. Flavour Fragrance J. 2005, 20, 676-685.

2. Guillen, M. D.; Errecalde, M. C. Volatile Components of Raw and Smoked Black Bream Brama raii and Rainbow Trout Oncorhynchus mykiss Studied by Means of Solid Phase Microextraction and Gas Chromatography/Mass Spectrometry. J. Sci. Food Agric. 2002, 82, 945-952.

3. Guillen, M. D.; Errecalde, M. C.; Salmeron, J.; Casas, C. Headspace Volatile Components of Smoked Swordfish Xiphias gladius and Cod Gadus morhua Detected by Means of Solid Phase Microextraction and Gas Chromatography-Mass Spectrometry. Food Chem. 2005, 94, 151-156.

4. Guillen, M. D.; Ibargoitia, M. L.; Sopelana, P.; Palencia, G.; Fresno, M. Components Detected by Means of Solid-Phase Microextraction and Gas Chromatography/Mass Spectrometry in the Headspace of Artisan Fresh Goat Cheese Smoked by Traditional Methods. J. Dairy Sci. 2004, 87, 284 299.

5. Guillen, M. D.; Palencia, G.; Ibargoitia, M. L.; Fresno, M.; Sopelana, P. Contamination of Cheese by Polycyclic Aromatic Hydrocarbons in Traditional Smoking. Influence of the Position in the Smokehouse on the Contamination Level of Smoked Cheese. J. Dairy Sci. 2011, 94, 1679-1690.

6. Majcher, M. A.; Jelen, H. H. Key Odorants of Oscypek, a Traditional Polish Ewe's Milk Cheese. J. Agric. Food Chem. 2011, 59, 4932-4937.

7. Varlet, V.; Knockaert, C.; Prost, C.; Serot, T. Comparison of Odor-Active Volatile Compounds of Fresh and Smoked Salmon. J. Agric. Food Chem. 2006, 54, 3391-3401.

8. Varlet, V.; Serot, T.; Cardinal, M.; Knockaert, C.; Prost, C. Olfactometric Determination of the Most Potent Odor-Active Compounds in Salmon Muscle Salmo salar Smoked by Using Four Smoke Generation Techniques. J. Agric. Food Chem. 2007, 55, 4518-4525. 
9. Alonge, D. O. Carcinogenic Polycyclic Aromatic Hydrocarbons (PAH) Determined in Nigerian Kundi (Smoke-Dried Meat). J. Sci. Food Agric. 1988, 43, 167-72.

10. Committee on Diet, Nutrition and Cancer, Assembly of Life Sciences, National Research Council. Diet, Nutrition and Cancer; National Academy Press: Washington, DC, 1982.

11. Griffiths, H. D.; Baines, D. A.; Parker-Gray, J. K. Smoked Food, Method for Smoking Food and Apparatus Therefor. WO 2015007742 A1, Jan 22, 2015.

12. Parker, J. K.; Lignou, S.; Shankland, K.; Kurwie, P.; Griffiths, H. D.; Baines, D. A. Development of a Zeolite Filter for Removing Polycyclic Aromatic Hydrocarbons (PAHs) from Smoke and Smoked Ingredients While Retaining the Smoky Flavor. J. Agric. Food Chem. 2018, 66, 2449-2458.

13. Institute of Food Technologists. Sensory Evaluation Division Sensory Evaluation Guide for Testing Food and Beverage Products. Food Technol. 1981, 50-59.

14. Brauss, M. S.; Linforth, R. S. T.; Cayeux, I.; Harvey, B.; Taylor, A. J. Altering the Fat Content Affects Flavor Release in a Model Yogurt System. J. Agric. Food Chem. 1999, 47, 2055-2059.

15. Ayed, C.; Martins, S. I. F. S.; Williamson, A.-M.; Guichard, E. Understanding Fat, Proteins and Saliva Impact on Aroma Release from Flavoured Ice Creams. Food Chem. 2018, 267, 132-139.

16. Schranz, M.; Lorber, K.; Klos, K.; Kerschbaumer, J.; Buettner, A. Influence of the Chemical Structure on the Odor Qualities and Odor Thresholds of Guaiacol-Derived Odorants, Part 1: Alkylated, Alkenylated and Methoxylated Derivatives. Food Chem. 2017, 232, 808-819.

17. Leffingwell, J. C.; Leffingwell, D. GRAS flavor Chemicals-Detection Thresholds. Perfum. \& Flavor. 1991 16, 1-19.

18. Poisson, L.; Schieberle, P. Characterization of the Key Aroma Compounds in an American Bourbon Whisky by Quantitative Measurements, Aroma Recombination, and Omission Studies. J. Agric. Food Chem. 2008, 56, 5820-5826. 